Mol. Cryst. Liq. Cryst., 1990, vol. 181, pp. 305-314

Reprints available directly from the publisher

Photocopying permitted by license only

(C) 1990 Gordon and Breach Science Publishers S.A.

Printed in the United States of America

\title{
EXAFS ANALYSIS OF SIZE-CONSTRAINED SEMICONDUCTING MATERIALS
}

\author{
KARIN MOLLER ${ }^{a}$, THOMAS BEINa ${ }^{a}$ NORMAN HERRON ${ }^{b}$, WALTER MAHLER ${ }^{b}$, JIM MAC \\ DOUGALLC, GALEN STUCKYC \\ a) Department of Chemistry, University of New Mexico, Albuquerque, NM 87131, \\ USA \\ b) Central Research and Development Department, E.I. DuPont de Nemours \& Co., \\ Wilmington, DE 19898, USA; Contribution No. 5385 \\ c) Department of Chemistry, University of California, Santa Barabara, CA 93106, \\ USA
}

Abstract Semiconducting materials such as $\mathrm{CdSe}, \mathrm{CdS}, \mathrm{PbS}$ and $\mathrm{GaP}$ are included in crystalline zeolite $Y$ and mordenite and structurally flexible ethylenemethacrylic acid copolymer solid matrices. EXAFS analysis reveals formation of species with dimensions of molecular size up to ca. $13 \AA$ in the crystalline hosts, while the polymer matrices allow agglomeration of larger semiconducting particles. Zeolite anchored structures are distinctively different to small particles with bulk crystal structure as usually found in colloidal systems.

\section{INTRODUCTION}

Small semiconducting clusters of nanometer dimensions represent a new class of materials with hybrid electronic and optical properties in comparison to their bulk and molecular counterparts. Widened electronic band gaps and the appearance of discrete absorption peaks in the electronic spectra of small semiconductor clusters have been interpreted as due to quantum size effects and exciton formation 1,2,3. Structurally defined semiconductors with homogeneous morphology and narrow size distribution are a prerequisite for understanding the physical origin of these effects.

The majority of previous studies have been performed on colloids. For example, small CdS particles of $35 \mathrm{~A}$ diameter could be prepared in aqueous solution by reaction of cadmium salts with $\mathrm{H}_{2} \mathrm{~S}$, but the colloids were found to be unstable against aggregation to $125 \AA$ within a day 4 . Some stabilization is obtained by arrested precipitation in non-aqueous solvents at low temperatures or upon addition of complexing agents (e.g., sodium hexametaphosphate) and stabilizers (e.g. colloidal silicon dioxide) $)^{5}$. Thus, even smaller CdS particles of 15 to $25 \mathrm{~A}$ diameter could be prepared in acetonitrile, with band gaps between 2.5 and $2.3 \mathrm{eV}^{6}$. Colorless "Q-CdS" 
particles $(Q=$ quantum state $)$ made in propanol at $-78^{\circ} \mathrm{C}$ were found to posess almost no semiconductor properties at all?. The latter are stable in solution, but very sensitive against light, heat and water. They can be obtained as solid materials only with simultaneous precipitation of cadmium sulfate which is believed to function as a spacer between the extremely small clusters. Larger particles, obtained by warming the alcoholic solution, showed photodissolution within minutes of illumination. The strong tendency to form larger aggregates could not be overcome by arrested precipitation in the case of $\mathrm{ZnSe}$ or $\mathrm{CdSe}^{8}$. In another approach, surfactants were used as stabilizers in order to aid charge separation in semiconductor colloids for application in photochemical solar energy conversion. Vesicles, or reversed micelles comparted CdS colloids were thus obtained of $550 \AA$ or $100 \AA$ diameter 9 .

Different routes have been explored to stabilize small semiconductor particles on supports: Crystalline particles of mainly 800 to 1000 A diameter have been reported on ultrathin bilayer lipid membranes ( $45 \mathrm{~A}$ ) which were stable for days. They could be removed from solution and arranged as arrays on copper grids ${ }^{10}$. Clays, which consist of stable two-dimensional sheets with ion-exchange capacity, present a potential for the formation of anisotropic semiconductors ${ }^{11}$. However, the flexibility of the interlayer spacing made the loading level of cadmium ions solvent dependent and reversible upon subsequent reaction with $\mathrm{Na}_{2} \mathrm{~S}$. When methanol was used as solvent the interlayer space was found to be too small to allow diffusion of $\mathrm{S}^{2-}$ anions and bulk CdS was formed on the external surface of the clay. The use of ethylene-methacrylic acid copolymer as matrix for PbS proved to be promising for a systematic control of particle size: films with colors ranging from black to yellow were obtained upon variation of the lead concentration and subsequent reaction with $\mathrm{H}_{2} \mathrm{~S}$. Band gaps from 1.0 to $2.2 \mathrm{eV}$ corresponding to particles estimated at 45 to $25 \mathrm{~A}$ were determined ${ }^{12}$. Monodispersed $20 \AA$ CdS particles were produced by an intriguing biosynthetic strategy using yeast bacteria ${ }^{13}$.

In order to obtain small semiconductor ensembles of defined size and structure, we have utilized zeolite hosts as stabilizing matrix. Zeolites are crystalline aluminosilicates with known pore sizes, cage structures and cation coordination sites and should therefore provide ideal hosts for this purpose. We have recently demonstrated that extremely small clusters of a variety of semiconductors such as Se, CdS, CdSe, PbS and GaP can be made using this approach $14,15,16,17,18$. The resulting materials, which are stabilized ensembles of only a few atoms, still exhibit exciton peaks in the electronic absorption spectra, characteristic for larger particles of ca. 20-50 A. In this report we discuss the different structural features of these materials as 
determined by EXAFS spectroscopy. Extended X-Ray Absorption Fine Structure Spectroscopy (EXAFS) has recently emerged as a technique to analyze systems lacking long range order ${ }^{19,20}$. It provides information about the close environment of the $x$ ray absorber atom by the following principle: Photoelectrons excited by $x$-ray absorption are backscattered to the absorber by atoms of the first few neighboring shells. The resulting interference wave pattern carries information about coordination numbers, distances and types of neighbors. A radial distribution function is obtained when EXAFS data are Fourier transformed from momentum space $\left(k, A^{-1}\right)$ to distance space $(r, A)$. The peaks in those functions are phase shifted by 0.3 to $0.5 A$ with respect to their real bond distances. Accurate structural information is extracted by iterative fitting with reference compounds. In the following we will describe the structures of (sub)nanometer particles of $\mathrm{CdSe}, \mathrm{PbS}$ and GaP clusters obtained by inclusion in zeolite or polymer matrices.

\section{EXPERIMENTAL}

The $\mathrm{Cd}$ and $\mathrm{Pb}$ samples were prepared via ion-exchange of $\mathrm{Cd}(\mathrm{II})$ or $\mathrm{Pb}(\mathrm{II})$ cations into zeolites $Y$, mordenite and/or a polymer matrix of $85 \%$ ethylene-15\% methacrylic acid copolymer (E-MAA) from aqueous solutions of $\mathrm{Cd}\left(\mathrm{NO}_{3}\right)_{2}$ or $\mathrm{Pb}\left(\mathrm{NO}_{3}\right)_{2}$ at room temperature. Subsequent dehydration of the zeolites at elevated temperatures and exposure to hydrogen sulfide/selenide at room temperature resulted in orange/yellow samples. Ga was introduced into zeolite $Y$ via gas adsorption of $(\mathrm{Me})_{3} \mathrm{Ga}$, which was then treated with 100 Torr of $\mathrm{PH}_{3}$ at $570 \mathrm{~K}$. EXAFS data were collected at the National Synchrotron Light Source, Brookhaven National Laboratories, beamline X-11A. The structural analysis was performed using experimentally determined EXAFS data from reference compounds.

\section{CASE IN ZEOLITEY ${ }^{16}$}

The formation of CdSe within the zeolite matrix was followed by studying both the dehydrated $\mathrm{Cd}$-exchanged precursor sample $\mathrm{CdY}$ and the same sample after reaction with $\mathrm{H}_{2} \mathrm{Se}$, CdSeY. Zeolite $\mathrm{Y}$ offers two different "reaction vessels" for cation coordination and cluster formation: "supercages" and sodalite cages with 13 and 6 A diameter, respectively. EXAFS analysis of the precursor sample CdY shows that $70 \%$ of all Cd cations are accomodated inside the sodalite cages. The corresponding Fourier transformed EXAFS spectrum is shown in Figure 1. 

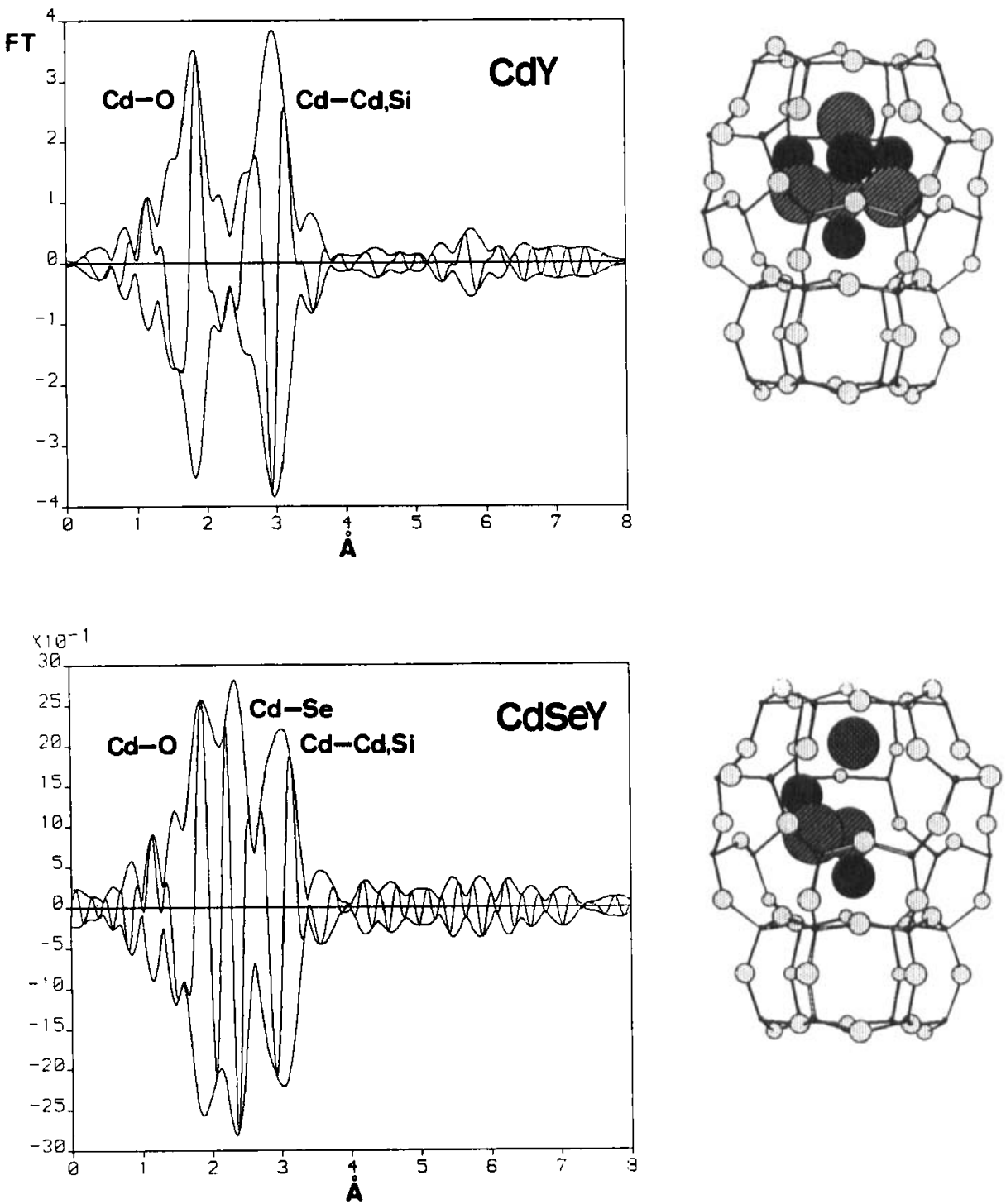

FIGURE 1 Radial distribution functions of cadmium exchanged zeolite $Y(C d Y)$ and, after treatment with $\mathrm{H}_{2} \mathrm{Se}$ ( $\mathrm{CdSeY}$ ). The corresponding three dimensional representations of cadmium ensembles in the sodalite cage are shown to the right: light dotted - Si framework atoms; large black - Cd ions; large striped - extraframework oxygen; large dotted - Se ion. 
The first peak in the precursor sample CdY originates mainly from two different oxygen neighbors of the cadmium ions. The second contribution is due to an overlap of a $\mathrm{Cd}$-Cd and $\mathrm{Cd}-\mathrm{Si}$ interaction, the latter arising from the zeolite framework. A threedimensional picture of the cation location in the zeolite framework is included in Figure 1. Cadmium ions (black) are coordinated to three oxygens at a distance of $2.44 \AA$ in front of Si-O-Si six-rings (SI' positions) in the sodalite units. The corresponding distance to the $\mathrm{Si}$ framework ions was found to be $3.42 \AA$. Additionally, cadmium is bound to extra-framework oxygen (dark striped; $\mathrm{OH}$ or $\mathrm{H}_{2} \mathrm{O}$ ) at $2.25 \mathrm{~A}$, thus forming a cube of $\mathrm{Cd}_{4} \mathrm{O}_{4}$ in the small cage of the zeolite. It seems that the oxygen shell of the sodalite units is well suited for saturation of the coordination sphere of the cadmium ions.

Upon introducing $\mathrm{H}_{2} \mathrm{Se}$, the EXAFS magnitudes corresponding to $\mathrm{Cd}-\mathrm{O}$ and $\mathrm{Cd}-\mathrm{Cd}$ interactions are reduced, and a new peak is present from an interaction of cadmium with selenium (Figure 1, CdSeY). Data analysis leads to the following conclusion: extra-framework oxygen is partially replaced by selenium ions, introducing strain to the initial $\mathrm{Cd}_{4} \mathrm{O}_{4}$ cube. Fragmentation into smaller entities and redistribution of cadmium is the result. Zeolite-anchored ensembles of $\mathrm{Cd}_{2} \mathrm{O}_{2} \mathrm{Se}$ in the sodalite cages (see Figure 1) and of CdSe in the supercage are the main products. The Cd-Se bond distance of $2.62 \AA$ is identical to the bulk value of $\mathrm{CdSe}$, but no indication exists for the formation of any bulk material. EXAFS analysis of the Se-edge also reveals the presence of small amounts of selenium helical chains. In contrast, when a similar $\mathrm{CdY}$ precursor sample is treated with $\mathrm{H}_{2} \mathrm{~S}$, the cube-like structure remains intact, but two oxygens are substituted for sulfur ions which are slightly smaller than selenium ${ }^{15}$. These results are consistent with synchrotron powder $X$-ray diffraction studies performed on the same samples ${ }^{16}$.

\section{PbS IN ZEOLITE Y, MORDENITE, AND METHACRYLLC ACID COPOLYMEB ${ }^{17}$}

EXAFS data at the $\mathrm{Pb}$ absorption edge were taken of the dehydrated lead precursor samples and after treating these samples with $\mathrm{H}_{2} \mathrm{~S}$. Data analysis of the precursor $\mathrm{PbY}$ shows that lead cations are coordinated to three oxygen atoms of the zeolite Si-O-Si sixrings with a $\mathrm{Pb}-\mathrm{O}$ bond distance of $2.46 \mathrm{~A}$, and a $\mathrm{Pb}-\mathrm{Si}$ distance of $3.42 \mathrm{~A}$, very similar to the cadmium coordination described above. The coordination sphere is completed by two additional extra-framework oxygens $\left(\mathrm{OH}\right.$ or $\left.\mathrm{OH}_{2}\right)$. The data suggest interaction with two to three lead ions at a distance of 4.1 and $4.3 \AA$. This long distance and the size of the cations points to a siting in the large cages which also contain six-ring windows. $\mathrm{PbO}$ cubes are thus not likely to exist, in contrast to the cadmium 
precursor samples. Exposure to hydrogen sulfide induces a rearrangement of the intrazeolite lead cations; all outer shell $\mathrm{Pb}$ - $\mathrm{Pb}$ interactions disappear. The resulting simple radial distribution function with an intense, broad peak is due to a convolution of $\mathrm{Pb}-\mathrm{O}$ and $\mathrm{Pb}-\mathrm{S}$ scatterers (see Figure 2, PbSY; $\mathrm{S}=\mathrm{H}_{2} \mathrm{~S}, \mathrm{HS}^{-}$or $\mathrm{S}^{2-}$ ).
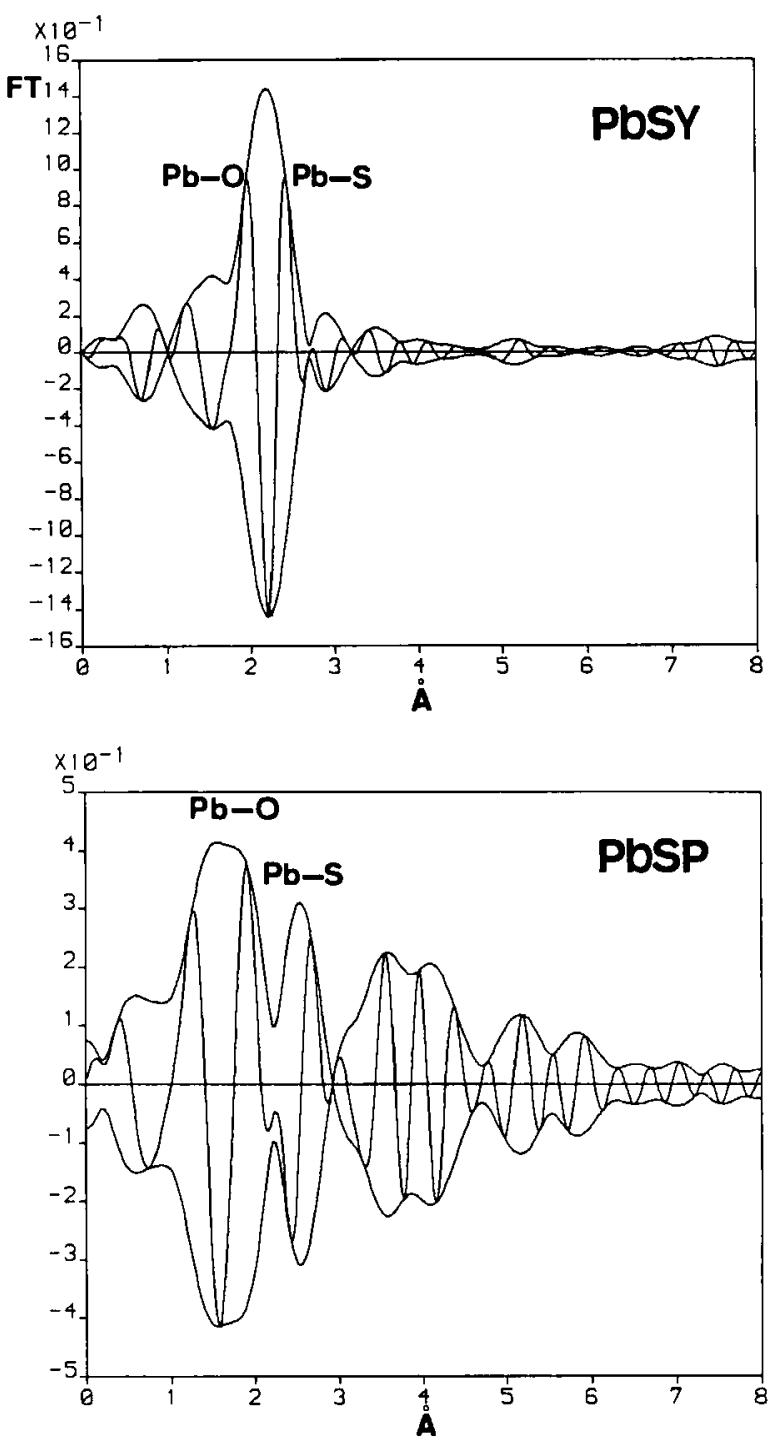

FIGURE 2 Radial distribution functions of lead sulfide in zeolite $Y$ (PbSY) and in ethylene methacrylic acid copolymer (PbSP). 
Lead ions are still anchored to the zeolite six-rings ( $\mathrm{Pb}-\mathrm{O}=2.47 \AA$ ) but have substituted their two non-framework oxygen ligands for two sulfur neighbors at a distance of $2.77 \mathrm{~A}$. This value is very short compared to the bulk value for PbS $(2.97$ $A)$, but is substantially longer than that for molecular $\mathrm{PbS}(2.29 \AA)^{21}$ and underscores the molecule-like nature of these ensembles. The overall reaction can be formulated as follows:

$$
\begin{aligned}
& \left(\mathrm{O}_{\mathrm{Z}}\right)_{3} \mathrm{~Pb}(\mathrm{OH})_{2}+2 \mathrm{H}_{2} \mathrm{~S} \leftrightarrow--\left(\mathrm{O}_{\mathrm{z}}\right)_{3} \mathrm{~Pb}(\mathrm{SH})_{2}+2 \mathrm{H}_{2} \mathrm{O} \\
& \left(\mathrm{O}_{2} \text { : zeolite oxygen }\right)
\end{aligned}
$$

As found earlier for selenium loaded zeolites ${ }^{14}$, there is no significant influence of the crystal structure of different zeolites on the coordination of the PbS species. Mordenite zeolites with one-dimensional channels would in principle offer the possibility to synthesize semiconducting "wires" in contrast to three-dimensional interconnects as conceivable in zeolite $Y$. However, the examined mordenite samples contain molecular ensembles almost identical to those found in zeolite $\mathrm{Y}$. It is possible that these ensembles communicate at higher loadings as indicated by optical data 22 .

The situation changes remarkably when $\mathrm{PbS}$ is formed in polymer films. If the corresponding EXAFS data (Figure 2, PbSP) are compared with those of zeoliteencapsulated lead sulfide, large outer-shell scattering is evident in the polymer samples. The backbone structure of the polymers is more flexible than the rigid inorganic framework of zeolites, and the cluster size of the semiconductor guests now depends strongly upon the metal concentration and heat treatment. It is evident from the radial distribution functions in Figure 2 that the cluster sizes of PbS in the polymer samples are much larger than those of molecular species found in the zeolites. Bond distances of the first $\mathrm{Pb}-\mathrm{S}$ atom pairs are close to the bulk value of $\mathrm{PbS}(2.99 \mathrm{~A})$, and outer peaks up to $6 \AA$ (uncorrected for phase shift) show good agreement with the lead sulfide bulk reference. The conversion to $\mathrm{PbS}$ is incomplete as indicated by the remaining $\mathrm{Pb}-\mathrm{O}$ contribution at a distance of $2.39 \AA$ that is due to polymer carboxylates and/or $\mathrm{PbO}$. Some of the outer shell scattering is unchanged with respect to the precursor sample and is probably due $10 \mathrm{PbO}$ particles. These results suggest that the limited permeability of the polymer may produce inhomogeneous $\mathrm{PbS}$ phases in addition to lead ions and lead oxide. It is interesting to note that the polymer and zeolite samples have very similar optical absorption spectra ${ }^{12}$. 


\section{GaPINZEOLITEY Y18}

Intrazeolite GaP was synthezised via vapor-surface reaction in the cavities of zeolite $Y$. $\left(\mathrm{CH}_{3}\right)_{3} \mathrm{Ga}$ was adsorbed in dehydrated $\mathrm{NaY}$ at room temperature to give the precursor sample MeGaY (see Figure 3). A single coordination shell is present in the EXAFS, resulting from a Ga-C contribution at $2.04 \AA$ of the adsorbed molecule.

Crystallographic data are not available for $\left(\mathrm{CH}_{3}\right)_{3} \mathrm{Ga}$, but the obtained distance agrees well with estimated data for interatomic distances. A rather high coordination number of 4.4 may indicate additional interaction with oxygen of the zeolite walls. $\mathrm{Si}^{29}$ NMR data suggest a strong interaction with the lattice by deformation of the TOT angle by 0.50. After treatment with $\mathrm{PH}_{3}$ at elevated temperatures $(470-670 \mathrm{~K})$ a color change from white to yellow-orange was observed. EXAFS data were taken of a sample heated at $570 \mathrm{~K}$. The resulting radial distribution function is shown in Figure 3 (GaPY). The observation of several coordination shells points to clusters larger than single GaP molecules. The position of the first shell $(2.04 \AA)$ is unchanged with respect to the precursor sample MeGaY, but is reduced in magnitude. Most likely this indicates the loss of methyl groups and the coordination of unreacted $\mathrm{Ga}$ ions to lattice oxygen. For sample GaPY a coordination number of 2.0 was found that correlates with $70 \%$ gallium ions sited in six-ring windows. A peak at ca. $2.5 \AA$ (uncorrected for phase shift) is believed to be due to the corresponding Ga-Si interaction. All other peaks in the distribution function can be explained with a GaP phase: Ga-P at $2.37 \AA$, Ga-Ga at 3.85 $\AA$ and a second Ga-P shell at $4.56 \AA$. These bond distances are very close to bulk GaP values. Based on the fraction that has reacted to GaP $(30 \%)$, and the coordination numbers for all neighboring shells, the cluster size can be estimated. A 30 atom GaP cluster with zinc blende structure has a diameter of about $11 \mathrm{~A}$. This estimated size agrees well with all fit results. A cluster this size can easily be accomodated in the large cavity of zeolite $Y$. We assume that the higher reaction temperatures facilitate the growth to supercage-sized clusters as compared to molecular ensembles formed at room temperature.

In conclusion, we have demonstrated that zeolites can be used as stabilizing matrix for subnanometer clusters ranging from framework-anchored molecular entities $\left(\mathrm{Cd}_{2} \mathrm{O}_{2} \mathrm{Se}, \mathrm{PbS}_{2}\right)$ to sodalite-encaged $(\mathrm{CdS}, \mathrm{O})_{4}$ cubes of $6 \mathrm{~A}$ size or GaP clusters of $11 \mathrm{~A}$ trapped in the supercages. In comparison, it seems more difficult to control the cluster formation in polymers, which tend to allow agglomeration of the semiconductor clusters. 

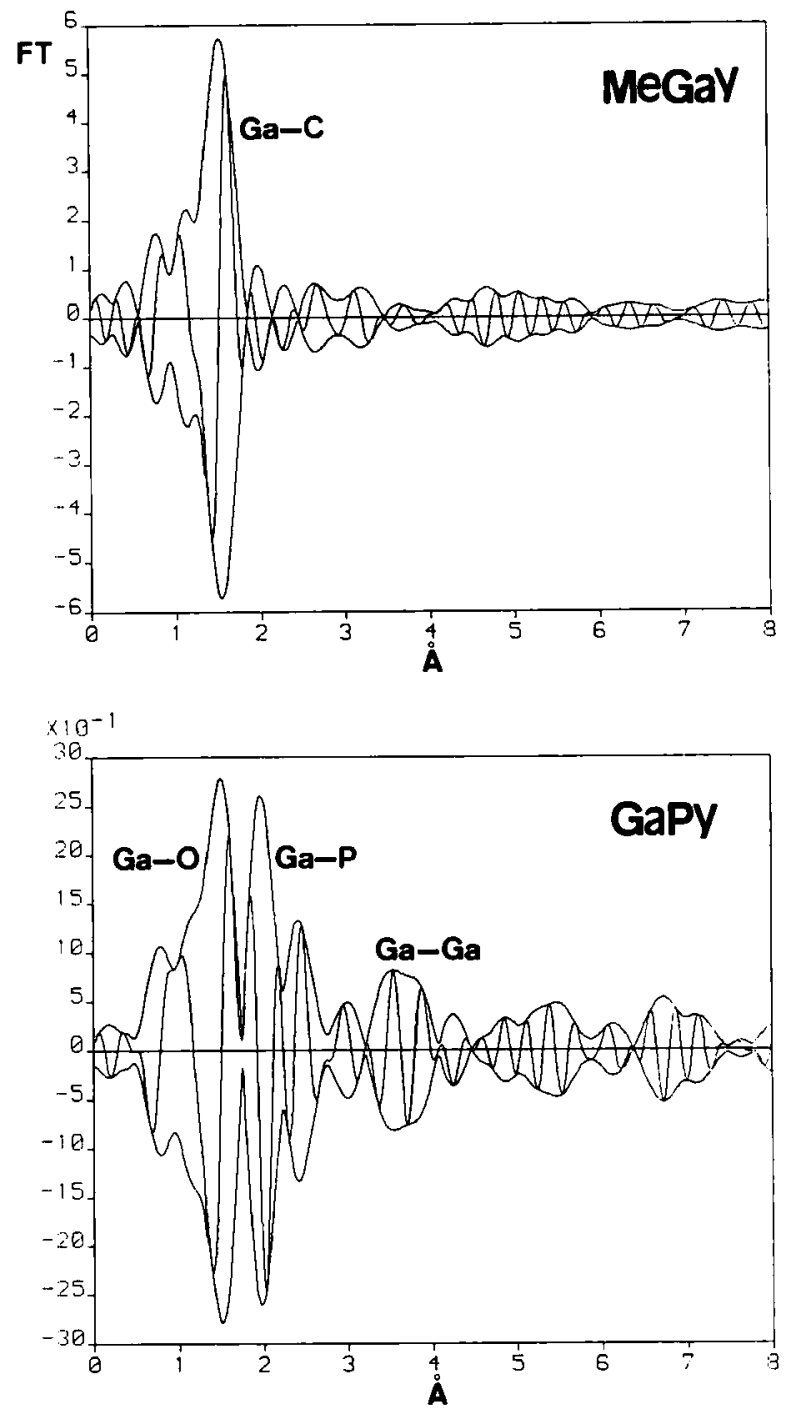

FIGURE 3 Radial distribution functions of $\left(\mathrm{CH}_{3}\right)_{3} \mathrm{Ga}$ loaded zeolite $\mathrm{Y}$ (MeGaY) and after treatment with $\mathrm{PH}_{3}$ at $570 \mathrm{~K}$ (GaPY). 


\section{Acknowledgment:}

Support provided by the Sandia-University Research Program (DOE; T. B., K. M.), by Du Pont (J. M., G. S.) and the office of Naval Research is gratefully acknowledged. The operational funds for NSLS beamline X11A are supported by DOE grant \# DEASO580ER10742.

1 L.E. Brus, J.Phys. Chem, 90, 2555 (1986)

2 J.M. Nedeljkovic, M.T. Nenadovic, O.I. Micic, A.J. Nozik, J. Phys. Chem. 90, 12 (1986)

3 A.J. Nozik, F. Williams, M.T. Nenadovic, T. Rahj, O.I. Micic, J. Phys. Chem. 89 , 397 (1985)

4 R. Rosetti, S. Nakahara, L.E. Brus, ل. Chem. Phys_, 79,1086 (1983)

5 R. Rosetti, R. Hull, J.M. Gibson, L.E. Brus, J. Chem. Phys. 83, 1406 (1985)

6 J.J. Ramsden, S.E. Webber, M. Grätzel, J. Phys. Chem. 89.2740 (1985)

7 A. Fojtik, H. Weller, U. Koch, A. Henglein, Ber. Bunsenges. Phys. Chem., 88. 969 (1984)

8 N. Chestnoy, R. Hull, L.E. Brus, J.Chem. Phys. 85, 2237 (1986)

9 a) Y.-M. Tricot, J.H. Fendler, J. Am. Chem. Soc. 106. 2475 (1984)

b) M. Meyer, C. Wallberg, K. Kurihara, J.H. Fendler, J. Chem. Soc. Chem. commun, 90 (1984)

10 X.K. Zhao, S. Baral, R. Rolandi, J.H. Fendler, J.Am. Chem. Soc, 110 1012 $(1988)$

11 X. Liu, J.K. Thomas, L. Colloid. Interface Science. 129, 476 (1989)

12 W. Mahler, Inorg. Chem. 27, 435 (1988)

13 C.T. Dameron, R.N. Reese, R.K. Mehra, A.R. Kortan, P.J. Carroll, M.L. Steigerwald, L.E. Brus, D.R. Winge, Nature_ 338, 596 (1989)

14 J.B Parise, J.E. Mac Dougall, N. Herron, R. Farlee, A.W. Sleight, Y. Wang, T. Bein, K. Moller, L.M. Moroney, Inorg. Chem. 27, 221 (1988)

15 N. Herron, Y. Wang, M.M. Eddy, G.D. Stucky, D.E. Cox, K. Moller, T. Bein, J.Am. Chem. Soc. 111530 (1989)

16 K. Moller, M.M. Eddy, G.D. Stucky, N. Herron, T. Bein, L. Am. Chem Soc. 111 2564 (1989)

17 K. Moller, T. Bein, N. Herron, W. Mahler, Y. Wang, Inorg. Chem. 28, 2914 (1989)

18 J.E. Mac Dougall, H. Eckert, G.D. Stucky, N. Herron, Y. Wang, K. Moller, T. Bein, D. Cox, L Am. Chem. Soc..111, 8006 (1989)

19 EXAFS Spectroscopy, edited by B.K. Teo, D.C. Joy (Plenum, New York, 1981)

$20 \quad X$-ray Absorption: Principles. Application. Techniques of EXAFS. SEXAFS and XANES, edited by D.C. Koningsberger, R. Prins (Wiley \& Sons, New York, 1987)

21 K.P. Huber, G. Herzberg, in Molecular Spectra and Molecular Structure IV. Constants of Diatomic Molecules, (Van Nostrand, New York, 1979) Y. Wang, N. Herron, L. Phys. Chem. 91, 257 (1987) 